\title{
Adaptation of Soil Physical Measurement Techniques for the Delineation of Mud and Lakebed Sediments at Neusiedler See
}

\author{
Ilse Kogelbauer ${ }^{1, *}$, Erwin Heine ${ }^{2}$, Christopher D'Amboise ${ }^{1}$, Christoph Müllebner ${ }^{1}$, \\ Wolfgang Sokol ${ }^{1}$ and Willibald Loiskandl ${ }^{1}$
}

1 Institute of Hydraulics and Rural Water Management, University of Natural Resources and Life Sciences, Vienna, Nußdorfer Lände 11, Vienna 1190, Austria;

E-Mails: christopher.damboise@gmail.com (C.D.); christoph.muellebner@gmx.at (C.M.); wolfgang.sokol@boku.ac.at (W.S.); willibald.loiskand1@boku.ac.at (W.L.)

2 Institute of Surveying, Remote Sensing and Land Information, University of Natural Resources and Life Sciences, Vienna, Peter-Jordan-Straße 82, Vienna 1190, Austria;

E-Mail: erwin.heine@boku.ac.at

* Author to whom correspondence should be addressed; E-Mail: ilse.kogelbauer@boku.ac.at; Tel.: +43-1-47654-5489.

Received: 20 October 2013; in revised form: 3 December 2013 / Accepted: 8 December 2013 / Published: 12 December 2013

\begin{abstract}
For many water management issues of shallow lakes with non-consolidated sediments hydrographic surveys of the open water area and reed belt areas are required. In the frame of water management strategy for the steppe lake Neusiedler See, located between Austria and Hungary, a hydrographic survey was conducted. In the open water area (water depth $\geq 1 \mathrm{~m}$ ) a sediment echosounder was used. To validate these measurements and to distinguish between water, mud, and sediment layers in the shallow lake and reed belt area additional measurements were needed. As no common standard methods are available yet, we developed a measurement system based on two commonly applied soil physical measurement techniques providing reproducible physical values: a capacitive sensor and a cone penetrometer combined with GNSS-positioning enable dynamic measurements of georeferenced vertical water-mud-bedsediments profiles. The system bases on site-specific calibrated sensors and allows instantaneous, in situ measurements. The measurements manifest a sharp water-mud interface by a sudden decline to smaller water content which is a function of the dielectric permittivity. A second decline indicates the transition to compacted mud. That is concurrently the density where the penetrometer starts registering
\end{abstract}


significant penetration resistance. The penetrometer detects shallow lakebed-sediment layers. Within the lake survey this measurement system was successfully tested.

Keywords: sediment profiles; mud layer delineation; shallow steppe lake; cone penetrometer; FDR; echo sounding

\section{Introduction}

There is a common interest on mapping and studying the bed constitution of natural water bodies, artificial harbours, or inland waterways for water management issues or navigability of shipping pathways, especially at the presence of a mud layer rich in fine-grained sediments. In the past, this non-consolidated, near-bottom mud layer was only assigned to few locations in channels, harbours and bays, but it is also a ubiquitous phenomenon in any natural water body [1]. It is present in any natural water body with sufficient supply of fine-grained sediment and periods of low flow velocity such as lakes and estuaries.

Acoustic techniques are extensively used in hydrographic surveys for lakebed mapping as they provide relatively rapid coverage of large lakebed areas compared to direct sampling methods [2,3]. But the inherent problem at the presence of a mud layer is the acoustic delineation and mapping of the lakebed surface. The mud density is slightly higher than that of water and increases gradually with depth [4], hence the impedance contrast offered to an acoustic wave by the water-mud-lakebed interface is less significant than by a water-lakebed interface. To overcome these difficulties of lakebed mapping McAnally et al. [4] emphasized the research need for improving or combining existing measurement techniques.

To support acoustic techniques for mud layer and lakebed mapping complementary methodologies with a soil physical approach are recommendable and have already been applied [1,3,4]. However, these methods require intensive sampling effort. So far there is no common standardized method that delineates water, mud and consolidated lakebed sediments at the presence of a distinctive transition zone from water to lakebed. Many studies reported the development of sensors that combine cone penetrometer with water content measurement systems such as time domain reflectrometry (TDR) or time domain transmissometry (TRT) [5-7]. All these presented probes and methods were developed for agricultural or mountainous forested soils [6,7], but not for surveying the challenging environment of a lake. Therefore some inadequacies of these probes for the intended application were their standardization, lack of ruggedness, accuracy of penetration resistance $P R$ measurement and obviously the very small maximal measurable depth of 40 to $60 \mathrm{~cm}$.

Thus, the purpose of the study was the adaptation of commonly used and well-known soil physical measurement techniques for the in situ delineation of mud and shallow lakebed-sediment layers within a hydrographic survey. This was accomplished by: (1) establishing a methodology; (2) the laboratory calibration of the sensors; (3) a measurement campaign with concurrent refinement of equipment, software, and measurement systematic; and (4) analyzing raw data to delineate mud and lakebed-sediment layers. 
The proposed measurement system consisted of a capacitive sensor determining the water content in soft mud and a cone penetrometer measuring the penetration resistance $P R$ in compact mud layers and lakebed sediments. It was joined together with a Global Navigation Satellite System (GNSS) Real-time Kinematic (RTK) positioning for dynamic, vertical point-measurements precise in location. The system of combined techniques enabled instantaneous, in situ survey to provide georeferenced, vertical profiles for mud and lakebed delineation of shallow water bodies with consolidated bed sediments. With this system many points high in their information quality could rapidly cover large lakebed areas with sufficient spatial resolution, but without extensive sampling effort.

This measurement system was applied within a hydrographic survey of the shallow steppe lake Neusiedler See and its surrounding reed belt located in the Pannonian Basin, along the border between Austria and Hungary. It was used as complementary measurements to validate echo sounding data, and to survey the very shallow water zones of the open water area (water depth $\leq 1 \mathrm{~m}$ ) as well as the surrounding reed belt. The hydrographic survey aimed to provide data for the water and reed management of the lake. Generally, the water management of the Neusiedler See is rather challenging in a focus on its extraordinary uniqueness together with multiple utilization interests such as water sports, tourism and agriculture.

\section{Methodology}

\subsection{Design of the Measurement System}

The main aim of the designed system is the delineation of water, mud, and lakebed-sediment layers at the Neusiedler See. The system utilizes three main components (Figure 1):

a. Sensor System: it consists of two well-known soil physical measurement techniques, a capacitive sensor (Hydra Probe, Stevens Water Monitoring System, Portland, OR, USA) and a modified penetrometer (Eijkelkamp, Giesbeek, Netherlands) [8] that measures water content and soil penetration resistance $P R$.

b. Data acquisition system: a data logger (CRX23, Campbell, North Logan, UT, USA) is used to collect and process data from the sensors and a GNSS RTK (GNSS RTK receiver/System 1200/Viva/GS25, Leica, Heerbrugg, Switzerland).

c. Software: the software is created to synchronize sensor data with GNSS position and convert it to a desired file format for further application.

The sensors are used consecutively at the same site to create instantaneously a vertical profile in the soft mud and the consolidated lakebed sediments. Each sensor is synchronized with position information from the GNSS System 1200/Viva/GS25 RTK System from Leica with accuracy of about $\pm 2 \mathrm{~cm}$ [9] using our therefore developed software tool GeneCon. Our method's advantages are obliviously precise location $(\mathrm{x}, \mathrm{y}, \mathrm{z}) \pm 3-5 \mathrm{~cm}$ in overall accuracy, dynamic in situ point-measurements and comparability due to values based on physical units. 
Figure 1. Scheme of the measurement system: sensors and electronic equipment for data acquisition (GNSS RTK receiver, data logger, notebook running GeneCon-software and power supply) stored in a splash-proof water-tight box.

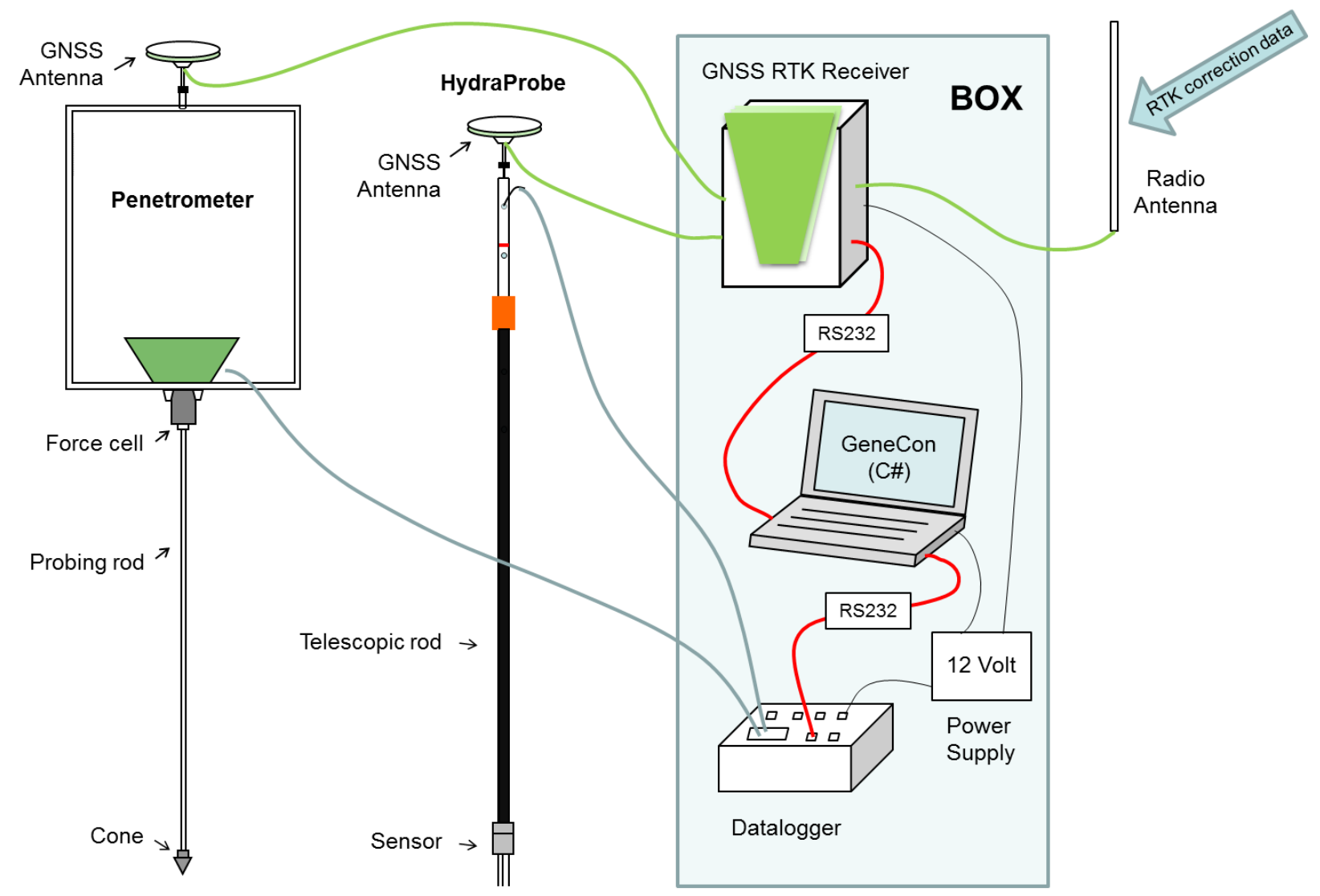

\subsubsection{Hydra Probe}

The Hydra Probe (Stevens Water Monitoring System), is a dielectric permittivity sensor based on frequency domain reflectometry (FDR) at $50 \mathrm{MHz}$ and indirectly indicates volumetric water content $\theta$ $\left(\mathrm{m}^{3} \cdot \mathrm{m}^{-3}\right.$ ) (sensor description see [10]). Usually it is applied for soil water monitoring in unsaturated conditions such as agricultural areas. For our application it is fixed on a telescope rod with a GNSS antenna mounted on top and used in saturated conditions to delineate air, water, and soft mud.

The Hydra Probe with analog output is used, because its rate of several measurements per second is faster compared to its digital counter parts (SDI-12 and RS-485) [11]. The output is transformed into the parameters (soil temperature measured by an internal thermistor, soil electrical conductivity, and dielectric permittivity). The directly measured relative complex dielectric permittivity, which composes of a real and an imaginary part, is further temperature corrected [12] and correlated to the soil water content [10]. The temperature corrected real part of the relative complex dielectric permittivity $\varepsilon_{r c o r r}$ enables the layer delineation by its significant difference; with $\varepsilon_{r}$ in air (1), Neusiedler See water (70-80), and solid particles (4-7).

It is proven that the relationship of probe length submersed in suspension and its output $\varepsilon_{\text {rcorr }}$ is highly linear [13] and thus an advantage. The sensor's reference point is set at the pins protruding base. 


\subsubsection{Penetrometer}

Cone penetrometers are recommended in the American Society of Agricultural Engineers (ASAE) Standards as a standard method for measuring the penetrometer resistance $P R$ of soils [14]. They are extensively used to evaluate soil strength especially in agriculture for resistance to root penetration [15], soil trafficability and soil compaction [16,17], but also for hydrogeomorphological surveying to identify depth of boundaries between layers [7]. In our case it should indicate dense layers to detect the lakebed surface and the shallow sub-bottom strata in combination with the sediment echosounder.

A penetrometer (Eijkelkamp, Art. Nr. 06.15.01) is modified twofold: the strain gauge is directly connected to the datalogger (Campbell CRX23) and the length of the probing rod is extended. A GNSS antenna is mounted on top of an aluminium frame, which is fixed on the splash-proven box accommodating the electrical components. The GNSS antenna is exactly aligned with the cone tip. The cone tip has a top angle of $60^{\circ}$, a diameter of $20.60 \mathrm{~mm}$ with a cross-sectional cone area $A p$ of $3.33 \mathrm{~cm}^{2}$ and a cylindrical shaft reduced in diameter to $20.08 \mathrm{~mm}$ [8]. The probing rod extensions are not exceeding the shaft with $14 \mathrm{~mm}$ in diameter and can be assembled by individual items of 0.5 and $1 \mathrm{~m}$ up to $5 \mathrm{~m}$ length.

The strain gauge, the central component of the penetrometer, is a force transducer returning output voltage, which differs from the basic voltage when deformation (either tension or compression) induces resistance changes. The output voltage is related to the weight force by laboratory calibration and measures the penetration resistance. The probing rod is fixed on the force transducer and can be put together for variable length, depending on the sludge depth. The maximum penetration resistance capacity of the force transducer is limited with $1,000 \mathrm{~N}$.

The pressure resistance $P R_{x}$ related to a penetrometer cone of a specific size is described by Equation (1) stated by Bradford [18]:

$$
P R_{x}=F_{p, x} / A_{p, x}
$$

where $F_{p, x}$ is the force required to push the penetrometer through the soil and $A_{p, x}$ is the cone's projected cross-sectional base area in $\mathrm{cm}^{2}$.

The $P R$ is influenced not only by the soil physical properties but also by the probe characteristics governing the friction. Friction inducing factors are the cone angle, the diameter of cone and shaft, roughness and penetration rate [18]. The $P R$ varies with soil factors such as bulk density, matric potential or water content, texture and organic matter, but is mainly influenced by the water content and bulk density [19]. Kosugi et al. [7] stated that the dependence of the $P R$ on the soil water content may mask the correlation of $P R$ to other soil properties; however this dependence is less prominent for the inherent saturated conditions at the measurement site.

\subsubsection{Data Acquisition System (DAS)}

Both sensors, the Hydra Probe and the Penetrometer, are connected to a Campbell CR23X data logger (sampling interval of $0.1 \mathrm{~s}$; data transfer RS232). Data from the data logger and the GNSS RTK receiver (NMEA data specification, $0.1 \mathrm{~s}$ data rate) are synchronized and stored with a C\# based software tool running in an attached notebook (Figure 2). The software is the core of the DAS, 
providing communication, control and validation functions. Software specifications are: command line; C\# with .NET4.0 or .Net3.5 Framework, WinXP or Win7 as operating system, Visual C\# 2008 Express Edition as development tool. The software contains three threads. One thread is responsible for receiving data from the Campbell CR23X logger (Rcv-Thread 1). The second thread receives data from the GPS 1200 (Rcv-Thread 2). The third and main thread is primarily responsible for synchronizing and storing the received data of equal time (Main-Thread). To make sure that only the newest data are processed the input buffer of the receiving threads are cleared after fetching data and the time out for receiving new data is set to $50 \mathrm{~ms}$. The baud rate for the two RS232 ports are set to 19,200 Bd (CR23X) and 57,600 Bd (GPS 1200). During the C\# software tool development it is ascertain that the latency time of the GNSS RTK System for providing the latest position data stays below $200 \mathrm{~ms}$. An acoustic signal announces that the data logger is ready and that the measurement can start. The signal indicates by its pitch the GNSS position quality and by its beat the data receiving interval. The power source and the electronic equipment are stored in a splash-proof box (see Figure 1).

Figure 2. Flow chart of data processing.

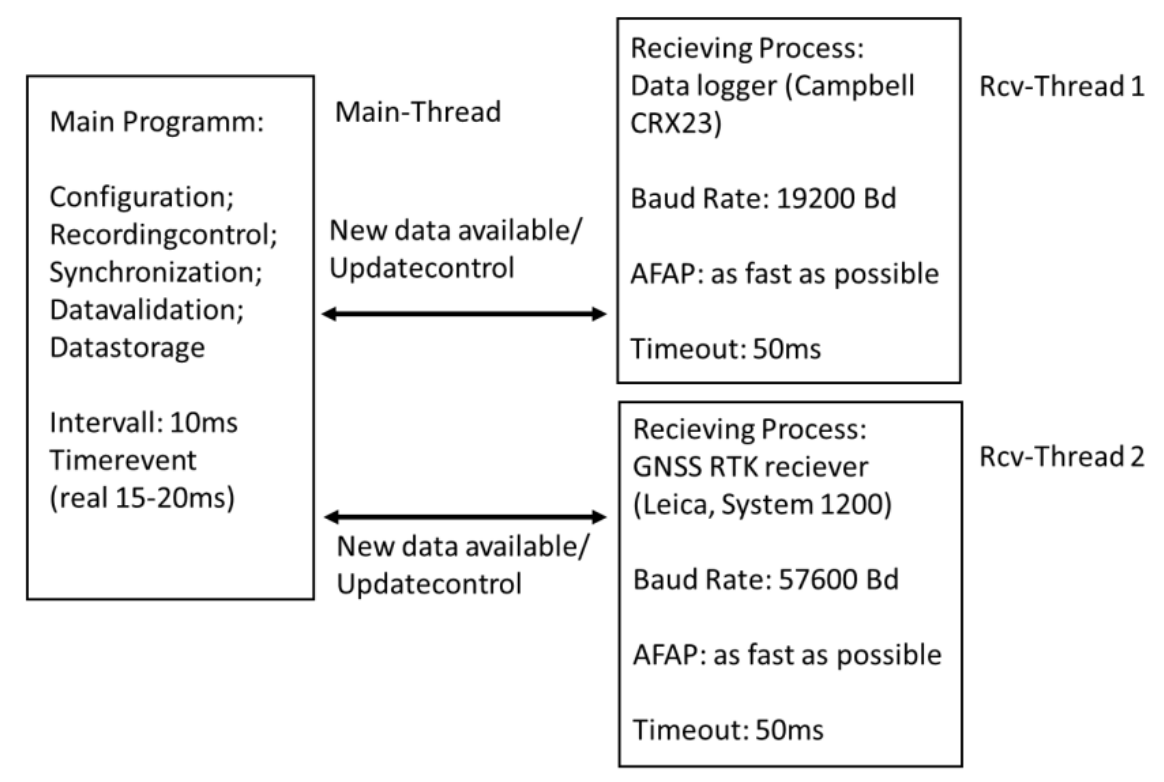

GNSS accuracy is increased by using RTK-correction signals which are emitted via radio antenna from GNSS base stations either in the North West or the South East of the lake.

\subsection{Study Site}

The Neusiedler See is the westernmost steppe lake in Central Europe surrounded by an extensive reed belt. It is located on Austrian and Hungarian territory in the flat terrain of the western part of the Little Hungarian Plain. The lake basin covers a total area of $321 \mathrm{~km}^{2}$ - at reference water level elevation $116.50 \mathrm{msl}$ (above Adriatic mean Sea level) [20]—including a reed belt of about $178 \mathrm{~km}^{2}$ overgrown with Phragmites australis [21]. The lake is very shallow, with water depths less than $2 \mathrm{~m}$. The lakes predominant characteristic is a huge stratified mud layer of mainly fine-grained sediments, which is a distinct transition zone between water and the lakebed. 
The water balance of the lake is dominated by precipitation and evaporation, and a natural inflow is either lacking or minor. Due to these facts the lake is prone to strong water level fluctuations and even to draught conditions, predominantly in summer at high evaporation rates [22]; however human interference, especially by water level regulation, is aside from climate the main source of desiccation and ecological consequences. Since the water level regulation in 1965 at the artificial weir within "Einserkanal", the only outflow (artificial) of the lake, an almost constant water level is reached. Within the period 1963-1988 almost doubling in mud volume on Austrian territory $\left(75 \mathrm{Mio} \cdot \mathrm{m}^{3}\right.$ to 150.17 Mio $\cdot \mathrm{m}^{3}$ ) was shown by Bácsatyai et al. [20]. The increase in sediments on Austrian territory is enhanced by wind-driven sediment shift and accumulation in the reed belt; silting up is even more intensified by massive increase of the reed belt area during 1901 to 1963 [20].

\subsection{Sensor Calibration}

\subsubsection{Hydra Probe Calibration}

The Hydra Probe calibration is particularly recommended for very wet soil with water content $>60 \%$ [23]. Hence it was calibrated for wet mud from the Neusiedler See relating the temperature corrected real part of the relative dielectric permittivity $\varepsilon_{\text {rcorr }}$ and the gravimetric measured volumetric water content $\theta\left(\mathrm{m}^{3} \cdot \mathrm{m}^{-3}\right)$ [24]. To account for the variation of mud composition throughout the lake, four mud types were considered in the calibration procedure. They were different in their particle size distribution (from clay to loamy sand) and organic matter with varying degree of decomposition. Two calibration methods were performed to gain a large range of water contents from compact to soft mud.

The calibration set of the first method M1 consisted of three mud samples taken from the South East edge of the lake: the first sample was taken from an organic rich top layer with many reed roots and plants, which was water saturated while sampling but subjected to periods of drying out during the year. Its particle size distribution is $21.66 \%$ sand $(0.05 \mathrm{~mm}$ to $2 \mathrm{~mm}), 25.37 \%$ silt $(0.002 \mathrm{~mm}$ to $0.05 \mathrm{~mm}$ ) and $52.97 \%$ clay (below $0.002 \mathrm{~mm}$ ). The second one was sampled from the more sandy layer with higher decomposed roots that lies just below the first one. The third sample was taken from about $1.5 \mathrm{~m}$ below the water surface from the lake bottom in an area close to an artificial canal; it contains $78.28 \%$ sand, $7.94 \%$ silt and $13.78 \%$ clay (average of five replicates). The second and third sample are similar in terms of texture and firmness.

Plastic jars of approximately one liter size were filled two-thirds full; to some jars dry mud or lake water was added and well mixed for more than $15 \mathrm{~h}$ with an electric tumble mixer to ensure homogeneity. The sensor was inserted into the samples ensuring that all the pins were completely covered. After the measurement the mud was filled in cylindrical metal rings of $200 \mathrm{~cm}^{3}$ (diameter $7 \mathrm{~cm}$, height $5 \mathrm{~cm}$ ) and oven dried at $105^{\circ} \mathrm{C}$ until mass constancy to measure the gravimetric water content and further calculate the volumetric water content $\theta$.

The second method M2 of calibration used mud samples extracted from deeper layers via a core sampler, where vacuum suction keeps the sample in the plastic tube. It was taken at the Eastern Side close to the reed belt at about $0.5 \mathrm{~m}$ water depth. The mud contains $26.18 \%$ sand, $32.75 \%$ silt and $41.07 \%$ clay. A 2 1-beaker was filled with mud until the mark of $600 \mathrm{~mL}$ and topped up with lake water until $700 \mathrm{~mL}$ and mixed with a spoon. Then the sensor was completely submerged in the mixture 
for the measurement. Again, the oven dried mass (at $105{ }^{\circ} \mathrm{C}$ and mass constant) was determined to calculate $\theta$. For broader range of water content the process was repeated 5 times using about $100 \mathrm{~mL}$ less mud (and $100 \mathrm{~mL}$ more lake water) for each run.

A third degree polynomial (Equation (2)) was fitted to the data pairs of $\varepsilon_{r c o r r}$ with $\theta$ obtained by both methods M1 and M2 $\left(R^{2}=0.9877\right)$ [24]. To fix the whole water content spectrum the lake water and oven dried ground mud were used as fixed points with assumed volumetric water content of $1 \mathrm{~m}^{3} \cdot \mathrm{m}^{-3}$ and $0 \mathrm{~m}^{3} \cdot \mathrm{m}^{-3}$ respectively. The Hydra Probe measurement error of $\varepsilon_{\text {rcorr }}$ was $\pm 1.5 \%$ or $\pm 0.2 \mathrm{~m}^{3} \cdot \mathrm{m}^{-3}$ whichever was greater. The measurement error of $\theta$ depend on the particle size, it is $\pm 0.01 \mathrm{~m}^{3} \cdot \mathrm{m}^{-3}$ or $\pm 0.03 \mathrm{~m}^{3} \cdot \mathrm{m}^{-3}$ for fine textured soils using the calibration provided by Stevens Water Monitoring System, Inc. [23]. The resulting calibration error for our application was $\pm 0.2 \mathrm{~m}^{3} \cdot \mathrm{m}^{-3}$ :

$$
\theta=-0.087968+0.027307 \varepsilon_{r}-0.000356 \varepsilon_{r}{ }^{2}+2.34 \times 10^{-6} \varepsilon_{r}{ }^{3}
$$

The clustering of similar points in Figure 3 obviously demonstrated that the mud composition had a significant influence on $\varepsilon_{r}-\theta$ relation. The mud composition varies throughout the lake in terms of organic matter content and its degree of composition, the particle size distribution, water saturation in periodically flooded areas. However, it was also recognized that highly organic mud samples had lower liquid consistency compared to its high water content than those samples with low organic content. The reason is probably due to a large fraction of water not free in soil pores, but retained in structures such as plant cells [24].

Figure 3. Fit of calibration function with a 3rd degree polynomial (all data points) [modified 24].

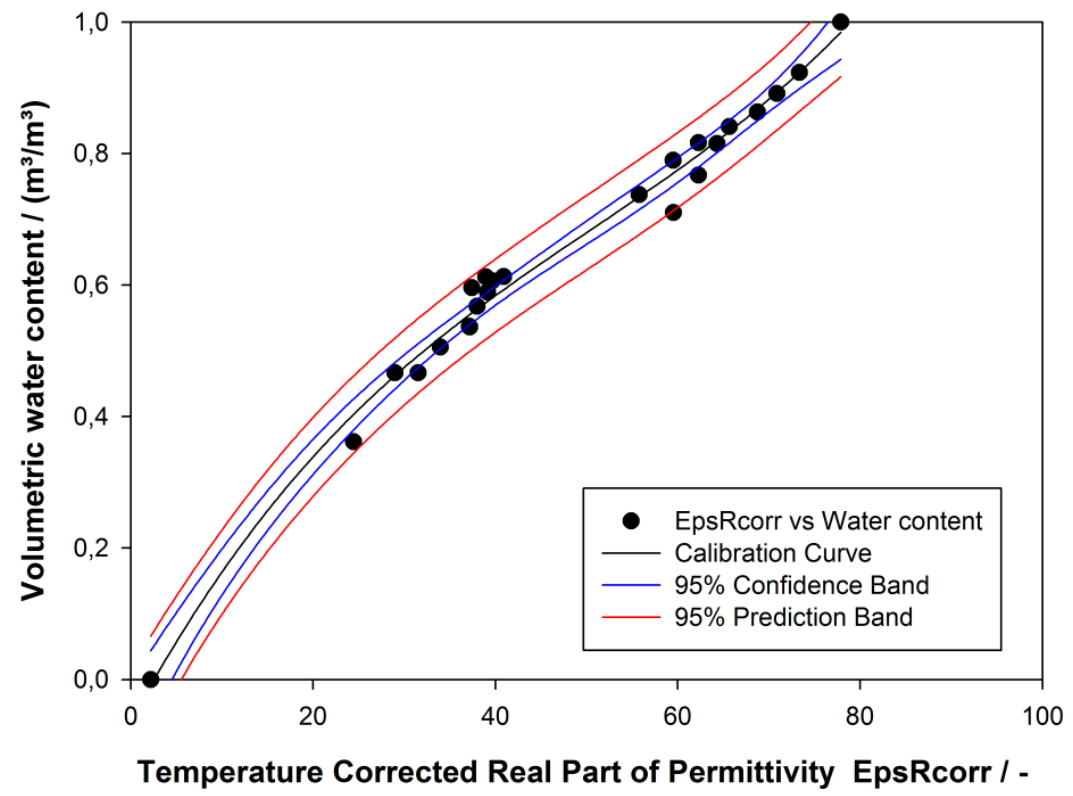

Investigations on the relation of water content and organic matter content need to be done to improve the exact determination of the water content. In our application the relative change of water content was sufficient for the layer delineation - water, mud, and bed sediment layers — as long as there was a significant change in $\varepsilon_{r}$. 
During field application at the beginning of the campaign, it was noticed that dried mud covering the pins reduced $\varepsilon_{r}$ readings significantly from about 0.75 to 0.6 for lake water. Hence, the sensors need to be cleaned carefully before the first measurement.

\subsubsection{Penetrometer Calibration}

The laboratory calibration relates the output voltage of the force transducer induced by the applied force. Therefore a removable wooden top part $20 \times 20 \mathrm{~cm}$ in dimension was fixed in the opening where the probing rod was connected with the force transducer. The maximum load-bearing capacity was $45 \mathrm{~kg}$. The force transducer was loaded with weight, left there for several seconds to eliminate randomly fluctuations. The base signal included the weight of the wooden top part of $535.3 \mathrm{~g}$. A weight $(5082+535.3 \mathrm{~g})$ was arranged centric and eccentric (nine positions in total). The mean average output voltage of $205.7 \mathrm{mV}$ for eccentric loading only varied $\pm 0.2 \mathrm{mV}$ from centric loading. The mean standard deviation was $2.7 \mathrm{mV}$ which is $1.3 \%$ of total voltage and also addresses the error for eccentric loading, which may occur under field conditions [25].

To obtain the linear calibration function (Equation (3)) the load of the force transducer was stepwise increased to $45 \mathrm{~kg}$ and afterwards reversely decreased:

$$
y=29.82 x+y_{0}
$$

where $y(\mathrm{mV})$ is the output voltage for the applied mass $x(\mathrm{~kg})$ with a changing offset voltage $y_{0}(\mathrm{mV})$ and $29.82 \pm 0.2 \mathrm{mV} \cdot \mathrm{kg}^{-1}$ as slope.

The influence of the probing rods weight was crosschecked. The output voltage induced by the tension force of the hanging rod of the penetrometer was compared with the voltage calculated by the calibration function. It was shown that also the tension force (negative voltage) was in a linear relation with $29.82 \pm 0.2 \mathrm{mV} \cdot \mathrm{kg}^{-1}$ to the output voltage [25]. The offset voltage of $18.40 \mathrm{mV}$ marginally shifted since its first operation, which might stem from a hysteresis due to material fatigue from the strain gauge. Therefore the base signal was identified every time starting an operation.

Further, the penetration resistance $P R$ in $\mathrm{MPa}$ was established based on Equation (1) using the calibration function (Equation (3)) with an additional factor $R_{p, x}(\mathrm{mV})$ for the weight of the probing rod:

$$
P R_{x}=\left(\frac{y-y_{0}+R_{p, x}}{29.82 \times A_{p, x}}\right) \times 0.09807
$$

We applied a conversion proposed by Bradford [18] to obtain the $P R_{x}$ in MPa from the output voltage. Hence, the factor 0.09807 implies the conversion from $\mathrm{kg} \cdot \mathrm{cm}^{-2}$ to $\mathrm{MPa}$ including gravity. The factor $R_{p, x}$ for the additional probing rod weight was considered to be $63.71 \pm 21.24 \mathrm{mV}$ for an average length of $3 \pm 1 \mathrm{~m}$. The marginal error evolving from that varying rod length of $\pm 0.2 \mathrm{MPa}$ or $2.1 \%$ was therefore tolerated.

\subsection{Field Data Collection}

The designed system was applied from a small boat for investigations at the open water surface and at the reed shore line whereas the reed belt was investigated with an adopted reed cutting machine. At 
the open water three replicates were made with both sensors to cover spatial variability. But to cover the lake-reed transition at least two measurements with each sensor where taken in the reed, at the edge and the water within a range of $6 \mathrm{~m}$ (boat length). In the reed at least three replicates with each sensor were measured at one spot. Mud core samples for soil physical and geological analyses and for the verification of the sensors' measurements were taken at specific spots.

\section{Results and Discussion}

\subsection{Hydra Probe}

The temperature corrected real part of the relative dielectric permittivity $\varepsilon_{r c o r r}\left(E p s R_{\text {corr }}\right)$ measured by the Hydra Probe (HP) supports the layer delineation in a murky suspension due to the significant difference in $\varepsilon_{r}$ of air, water, and solid particles. In our case of saturated conditions the measured volume only consists of solid particles and water. Thus $\varepsilon_{r}$ plainly indicates the fraction of solids and water due to the significant difference in $\varepsilon_{r}$, which is 3 for dry soil and about 80 for lake water. Variations of $\varepsilon_{\text {rcorr }}$ in the lake are induced by the temperature, but even more by the inherently high electrical conductivity $E C$. The $E C$ is higher than $2,000 \mu \mathrm{S} / \mathrm{cm}$ with maxima at about $3,000 \mu \mathrm{S} / \mathrm{cm}$ and induces $\varepsilon_{\text {rcorr }}$ to vary from 65 to 80 .

In Figure 4 unfiltered data of five replicate Hydra Probe measurements at point P053 in the open water area (Illmitz; Universal Transverse Mercator (UTM) coordinate system: 33N 629812 5291320) explains the inherent measurement procedure. Each measurement starts in air, so the current water surface can be observed when the sensor is submerged into water, which is a valuable side effect. Further submersion in water at almost constant $\varepsilon_{\text {rcorr }}$ of 66 (occurring range 65 to 80 ) is interrupted by a sudden decline in $\varepsilon_{\text {rcorr }}$ to about 48 (occurring range 45 to 60 ) indicating the water-mud interface (mud surface). Then the ongoing submersion continuous in the mud layer till the mechanical resistance prevents further penetration of the sensor in more compact mud layers and the lakebed sediments.

At the water-mud interface the sensor pins are fully submerged in the mud and the base of the sensor's cylindrical body is aligned with the interface. Consequently, it is at the decline's low $\varepsilon_{\text {rcorr }}$ value. The $\varepsilon_{r c o r r}$ in the mud layer is almost linear, just slight variance due to spatial variability occurs.

The same trend is given for all replicates (Figure 4). The air-water interface (water surface) is at $115.39 \mathrm{msl}$ (above Adriatic mean Sea level), the water-mud interface (mud surface) is at $113.80 \mathrm{msl}$ and the deepest point of submersion is at $113.16 \mathrm{msl}$, all as average of five replicates. Thus the mean thickness of water and soft mud are $1.59 \mathrm{~m}( \pm 0.01 \mathrm{~m})$ and $0.64 \mathrm{~m}( \pm 0.03 \mathrm{~m})$, respectively. In air the measurements are diverging slightly, a phenomenon related to the moving barge with the waves and is in an average range of $0.16 \mathrm{~m}( \pm 0.04 \mathrm{~m})$ (Table 1).

The Hydra Probe calibration function determined in the laboratory was validated in the field at two random locations at the reed belt shore adjacent to the lake. At each location core cylinder samples were taken next to the in situ measurements with the Hydra Probe (three replicates). Location A was sandy with lots of fine reed roots ( $\mathrm{mm}$ in diameter) compared to Location B high in silt and clay with many medium roots (diameter approx. $0.5-1 \mathrm{~cm}$ ) causing numerous holes containing water. The agreement between the volumetric water content determined by the Hydra Probe (HP Theta) and gravimetrically determined from cylindrical cores (CC Theta) was checked (Figure 5). Due to 
spatial heterogeneity small deviations were evident, but still staid in a reasonable average limit of -0.047 in Location A and 0.026 in Location B. In A HP Theta overestimated CC Theta while in B it underestimated. This phenomenon can be explained due to non-optimal conditions of core sampling (Figure 5). But also volume reduction by shrinking, weight reduction due to lower particle density of organic material, and roots containing water were observed.

Figure 4. Hydra Probe measurements are used for layer indication of air, water, mud, and bottom bed. A steep decline in $\varepsilon_{\text {rcorr }}\left(\mathrm{EpsR}_{\text {corr }}\right)$ indicates the water-mud interface. Another decline occurs when mechanical resistance of compact mud and the lakebed sediments prevent further submersion. Point P053.

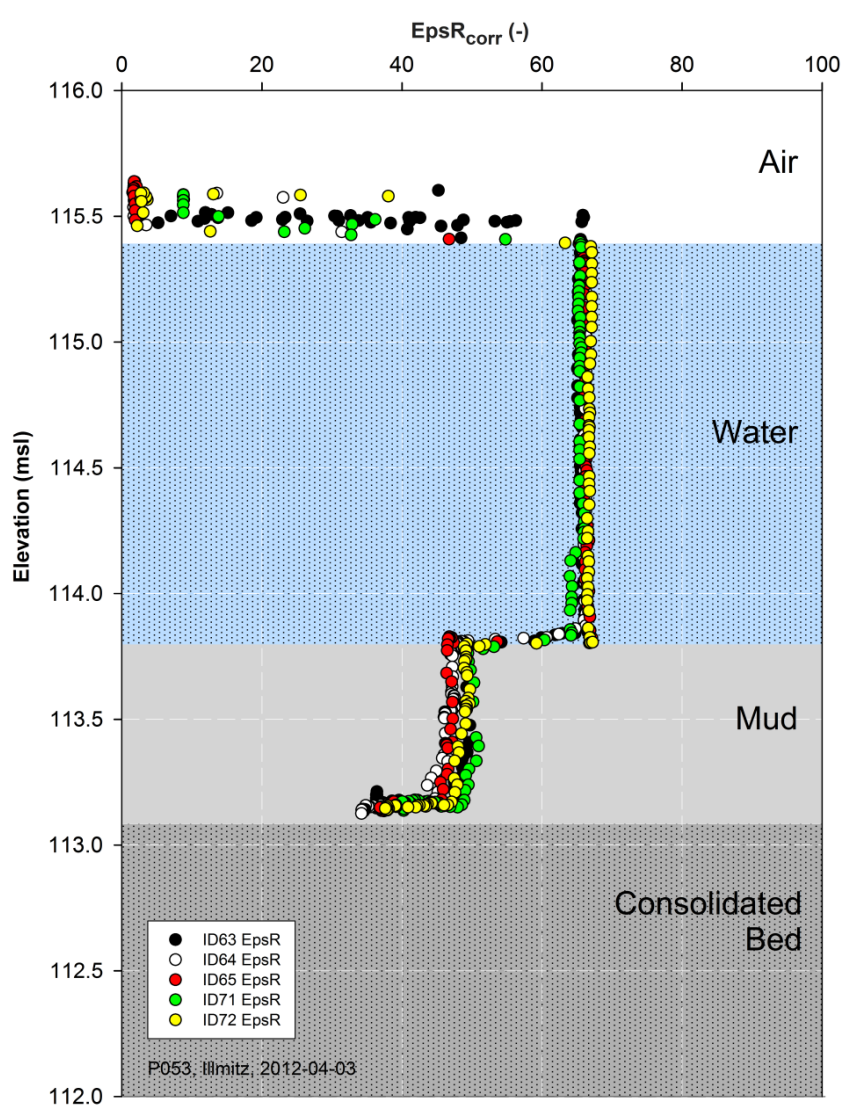

Table 1. Mean interface elevation ( $\mathrm{msl}$ ) and mean layer thickness $(\mathrm{m})$ indicated by changes in $\varepsilon_{\text {rcorr }}$ that delineate air, water, and mud in point P053.

\begin{tabular}{lcclccc}
\hline & \multicolumn{2}{c}{ Interface } & & \multicolumn{2}{c}{ Layer Thickness } \\
\cline { 2 - 3 } \cline { 5 - 6 } & Elevation (msl) & $\boldsymbol{\varepsilon}_{\text {rcorr }}(-)$ & & Thickness (m) & $\Delta \boldsymbol{\varepsilon}_{\text {rcorr }}(-)$ \\
\hline Air-Water $^{\text {a }}$ & $\mathbf{1 1 5 . 3 9}$ & 65.75 & Waves & $\mathbf{0 . 1 6}$ & \\
& $(0.01)$ & $(0.61)$ & & $(0.04)$ & \\
Water-Mud & $\mathbf{1 1 3 . 8 0}$ & 48.77 & Water $^{\text {a }}$ & $\mathbf{1 . 5 9}$ & 16.98 \\
& $(0.01)$ & $(0.92)$ & & $(0.01)$ & $(0.90)$ \\
HP Stop $^{\mathrm{b}}$ & $\mathbf{1 1 3 . 1 6}$ & 37.03 & HP Mud & $\mathbf{0 . 6 4}$ & 11.74 \\
& $(0.03)$ & $(1.88)$ & & & $(0.03)$ & $(1.61)$ \\
\hline
\end{tabular}

Note: Interface elevation and layer thickness are average values of five replicates. Standard deviations are given in parentheses. ${ }^{a}$ The air-water interface (water surface) and the water layer thickness (water depth) only account for the day of measurement 3 April 2012; ${ }^{b}$ HP (Hydra Probe) Stop is the submersion end due to mechanical resistance in compact mud. 
Figure 5. The field validation compares the volumetric water content determined with the calibrated Hydra Probe (HP Theta) and gravimetrically determined from cylindrical cores

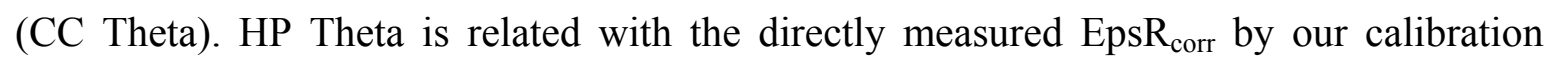
function. Two locations different in core size distribution and root content at the shore of the reed belt were sampled (A, B).

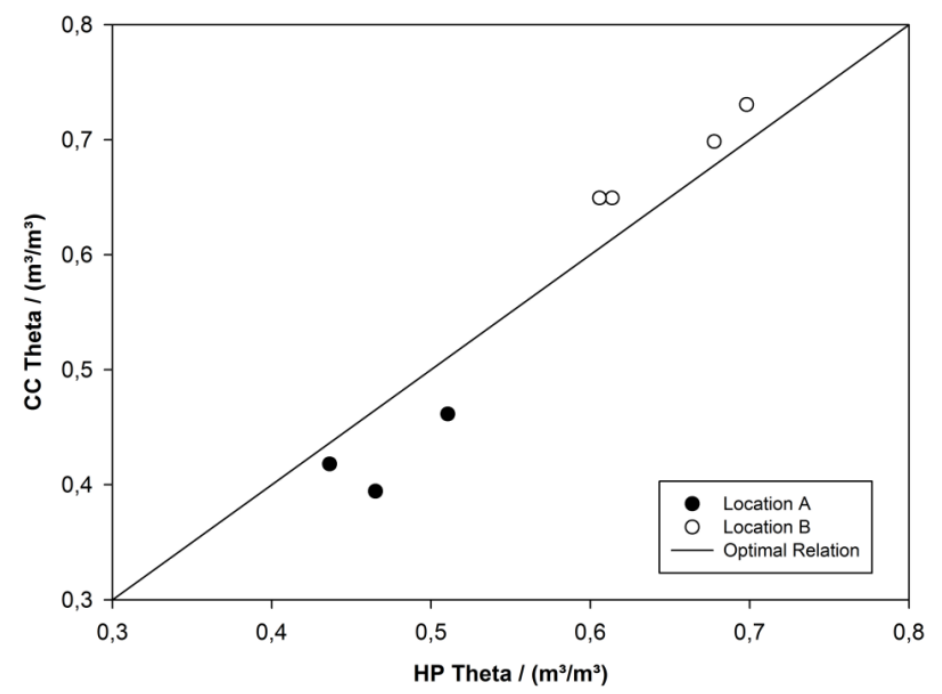

\subsection{Penetrometer}

Pressure resistance $P R$ is the significant factor for detecting lakebed surface and shallow lakebed-sediment layers. A sharp increase in the $P R$ of the penetrometer indicates a compact layer, much more compact than a soft mud layer where the $P R$ is too low to be detected.

In Figure 6 raw data of five replicate measurements at the same point P053 as for the Hydra Probe measurements are shown. Each penetrometer measurement starts in water or soft mud at minimal pressure resistance and rapidly increases when reaching more compact shallow layers with higher density. The point of detecting significant $P R$ coincides with the submersion end of the Hydra Probe sensor, thus a continuous vertical mud-sediment profiling is gained with both sensors (Figure 6). Layers of high or low density can occur in between the shallow top layer and the very end of penetration. At point P053 the mud-lakebed interface (lakebed surface) is at $113.08 \mathrm{msl}( \pm 0.01 \mathrm{~m})$, which results in a final mud layer thickness of $0.72 \mathrm{~m}( \pm 0.02 \mathrm{~m})$ (Table 2). Another consolidated lakebed-sediment layer is at $112.78 \mathrm{msl}( \pm 0.02 \mathrm{~m})$. Nevertheless, the detection of shallow layers is achieved by this setup although maximal rod length of up to $5 \mathrm{~m}$ and rod diameter are restricted to manual operation. Besides the probing rod length, the lateral bending resistance of the rods, the highest possible applied pressure, and man power are other external factors limiting the measurement depth.

The penetrometer graph (Figure 6) comprises only raw data visibly quite unsteady, that arises from handling, and needs some additional filtering. Inconsistency in elevation is mainly observed at dense layers when breakthrough and rapid falling is accompanied by interruption of GNSS data processing. The reason is the acceleration in submersion-velocity, because the GNSS RTK receiver generates precise elevation data of dynamic processes by forward calculation assuming constant velocity. It appears as loops that can easily be differentiated from soft layers for two reasons: a very small elevation difference of few $\mathrm{cm}$ and the lack of GNSS elevation data when the pressure readings jump 
back. Moreover short term relief evolves when the person changes position while pushing the penetrometer down. However, dense layers are mainly identified by a significant relative change in $P R$ and less due to defining absolute values of $P R$.

Figure 6. Penetrometer measurements (five replicates) are used for the detection of lake bottom and shallow sub-bottom strata in Point P053. A significant relative change in $P R$ indicates layers different in their density or degree of compaction. The detection of significant $P R$ coincides with the submersion end of the Hydra Probe.

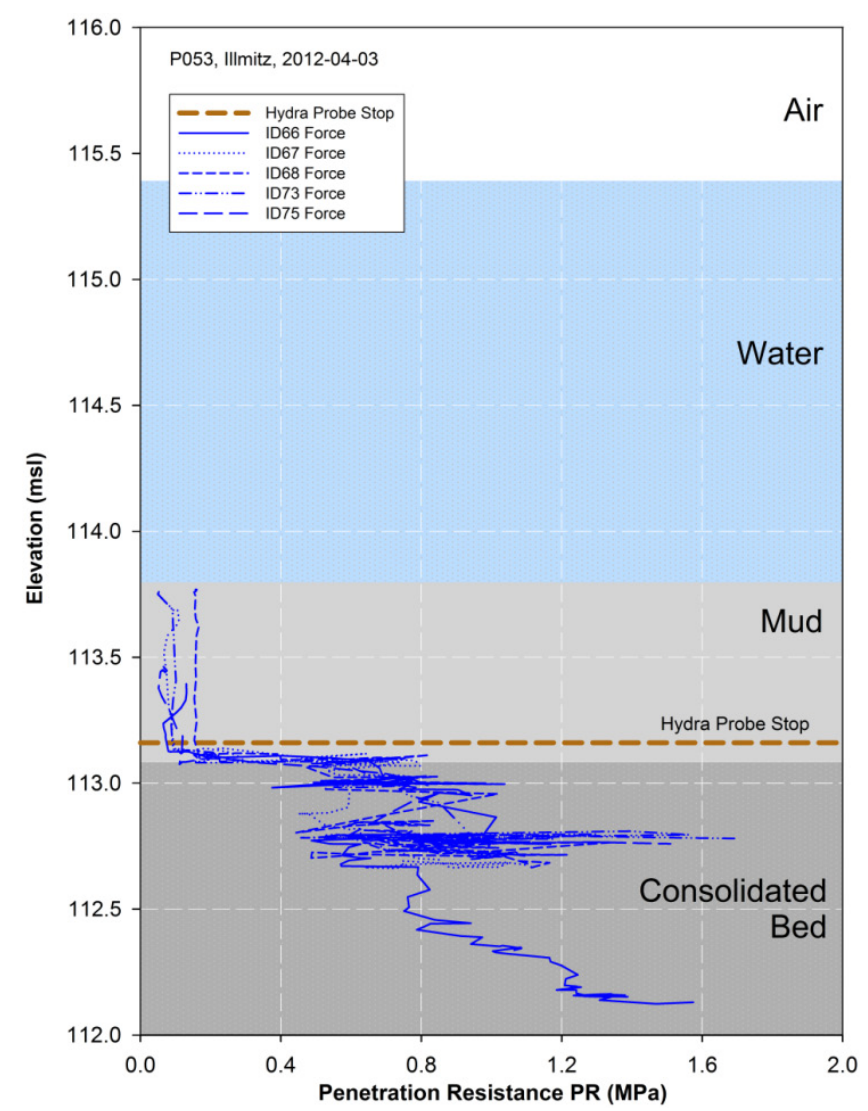

Table 2. Mean interface elevation ( $\mathrm{msl}$ ) and mean layer thickness ( $\mathrm{m}$ ) indicated by changes in $P R$ to delineate the lake bed surface and shallow lake bed sediment layers in point P053.

\begin{tabular}{|c|c|c|c|c|c|}
\hline & \multicolumn{2}{|c|}{ Interface } & & \multicolumn{2}{|c|}{ Layer Thickness } \\
\hline & Elevation (msl) & $P R$ (MPa) & & Thickness (m) & $P R$ (MPa) \\
\hline Mud-Lakebed & 113.08 & 0.70 & Mud total $^{\mathrm{a}}$ & 0.72 & \\
\hline & $(0.01)$ & $(0.07)$ & & $(0.02)$ & \\
\hline Bed Layer & $\begin{array}{c}\mathbf{1 1 2 . 7 8} \\
(0.02)\end{array}$ & $\begin{array}{c}1.33 \\
(0.21)\end{array}$ & Bed Layer & $\begin{array}{c}\mathbf{0 . 3} \\
(0.02)\end{array}$ & $\begin{array}{l}-0.60 \\
(0.22)\end{array}$ \\
\hline
\end{tabular}

Note: Interface elevation and layer thickness are average values of at least three replicates. Standard deviations are given in parentheses. ${ }^{\text {a }}$ The total thickness of the mud layer considers the water-mud interface (Table 1) at $113.80 \mathrm{msl}$. 


\subsection{Validation of Echo Sounding in the Open Water Area}

For the acoustic mapping of the lakebed at the Neusiedler See a Single Beam Echosounder (SBES) at frequencies of $710 \mathrm{kHz}, 200 \mathrm{kHz}$, and $100 \mathrm{kHz}$ and additionally a Sub Bottom Profiler (SBP) at $10 \mathrm{kHz}$ were used at the open water area [26]. The applied SBES, a parametric acoustics unit of the Innomar SES-2000 sediment echosounder, gave an excellent resolution and good penetration into the

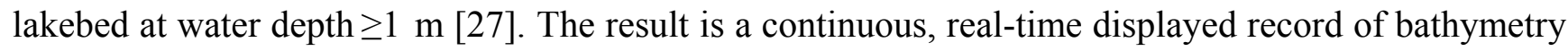
that illustrates the first significant reflecting interface in the water-mud transition and further reflecting sediment interfaces between sub-bottom strata [2]. The reflection of acoustic energy takes place at interfaces of differing acoustic impedance, and the reflection strength depends on the degree of impedance contrast [2]. The inherent problem at the presence of a mud layer is the acoustic delineation and mapping of the mud and lakebed surface due to low impedance contrast explained by small density gradients. Thus the complementary, soil physical measurements support the layer delineation of the echo sounding.

Figure 7. Example of preliminary layer validation by correlating the SBP echogram sequence (Left) including the validation-point P053 with the soil physical measurement system (Right). The layering in the echogram indicated by red-yellow, which visualizes strong reflections due to high impedance contrast, coincides reasonable well with the soil physically determined interfaces.

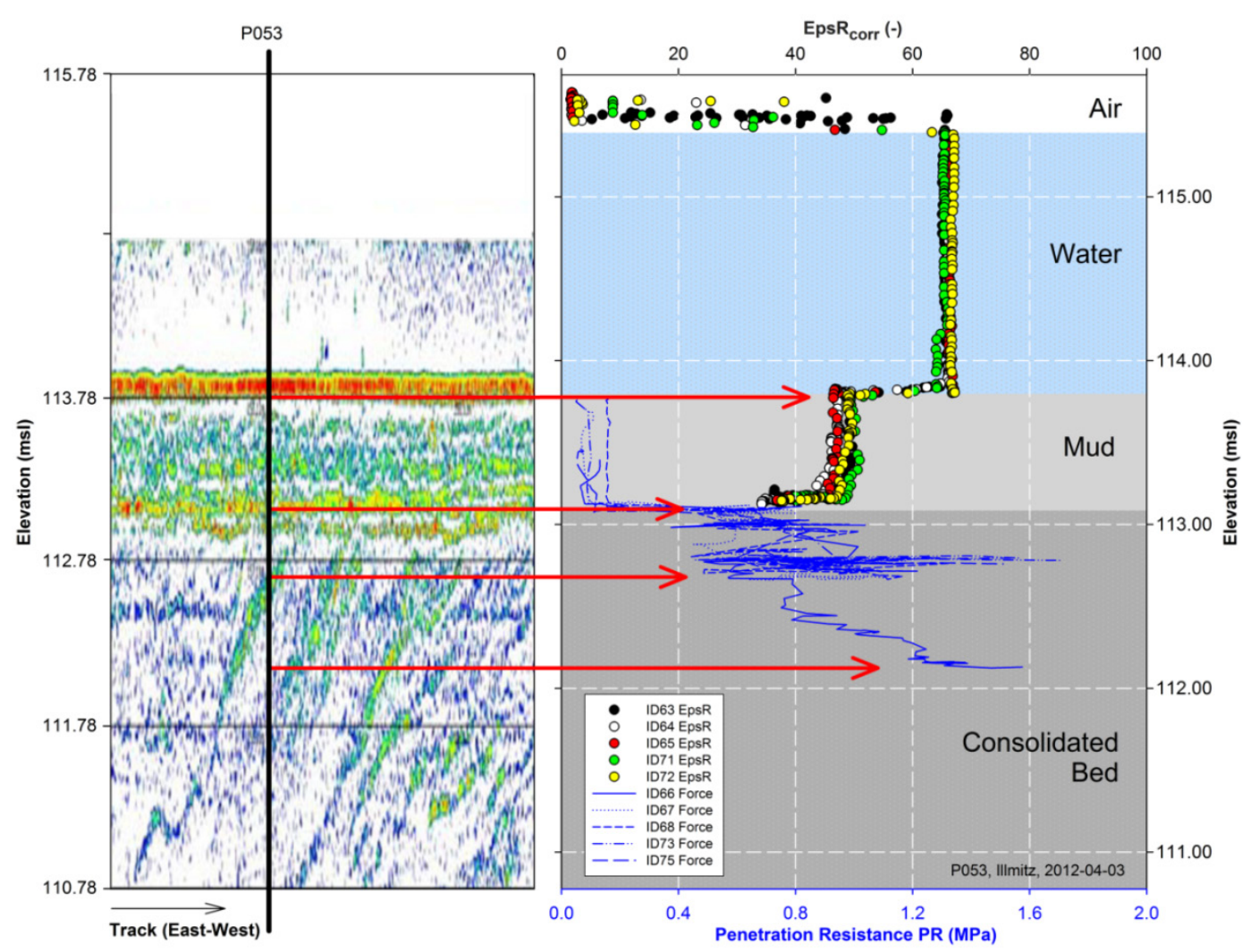

SBES and SBP tracks were measured in a raster from $(500 \mathrm{~m} \times 100 \mathrm{~m})$ in the open water areas at a minimum water depth of $30 \mathrm{~cm}$ (SBES) and $1 \mathrm{~m}$ (SBP). About 60 validation-points were selected for the soil physical measuring campaign in spring 2012 based on the echosounder tracks. At each 
validation-point at least 2 to 3 replicate measurements with the Hydra Probe and the penetrometer were taken to detect possible spatial variability.

The low frequency SBP echogram sequence (Figure 7) shows an example of a layer validation. The echogram color pattern visualizes differences in the density of sediment layers by a colour scale from blue (weak reflections) to red (strong reflections). The vertical line in the echogram shows the location of the validation-point P053 of the soil physical measurements. The blank top part of the echogram (115.78-114.78 msl) evolves due to the minimal operation depth of the SBP in the water body. The first significant reflection follows at height $113.93-113.78 \mathrm{msl}$ in red-yellow colour that coincides with the mud surface detected at $113.80 \mathrm{msl}$ by the Hydra Probe. Further significant reflection signal coincides with the lakebed surface at $113.08 \mathrm{msl}$. Beneath that, a significant reflection coincides with an increase in $P R$ at $112.78 \mathrm{msl}$. Overall in point $\mathrm{P} 053$ a good correlation of the echogram with the soil physical measurement data-Hydra Probe and the penetrometer-is demonstrated.

\section{Conclusions}

A new measurement system for delineating mud and lakebed sediments was developed and successfully tested. The new set up enables instantaneous measurements of water content and penetration resistance at shallow water bodies, which are rich in non-consolidated fine-grained sediment layers. Georeferenced vertical profiles for layer delineation of water, mud, and shallow lakebed sediments are obtained. The system provides a high information quality at a measurement point and benefits from the combination of two already standardized soil physical methods that support comparability and reproducibility. Moreover, it is less time consuming and requires minimal sampling effort when covering large areas in sufficient spatial resolution. However, in data interpretation and interface delineation significant relative changes in the physical values $-\varepsilon_{r c o r r}$ and $P R$ - are used rather than absolute values. It was shown that the validation of echo sounding data was supported by this adapted measurement system for the application at the steppe lake Neusiedler See. Generally, it worked out well and the good correlation proposed further data validation. Finally, the developed methodology offers an adequate and reliable in situ approach for surveying campaigns to delineate and map mud and lakebed sediments.

\section{Acknowledgments}

We thank our project partners in Austria and Hungary for their good cooperation. We are thankful for the technical support and facility provision of the Biological Station Illmitz. We are particularly thankful for the support and outstanding personal commitment from the boat drivers and the measuring assistants during the field measurement campaigns.

\section{Conflicts of Interest}

The authors declare no conflict of interest. 


\section{References}

1. McAnally, W.H.; Asce, F.; Friedrichs, C.; Hamilton, D.; Hayter, E.; Shrestha, P.; Rodriguez, H.; Sheremet, A.; Teeter, A. Management of fluid mud in estuaries, bays, and lakes.:IPresent state of understanding on character and behavior. J. Hydraul. Eng. ASCE 2007, 133, 9-22.

2. Penrose, J.D.; Siwabessy, P.J.W.; Gavrilov, A.; Parnum, I.; Hamilton, L.J.; Bickers, A.; Brooke, B.; Ryan, D.A. Acoustic Techniques for Seabed Classification; Technical Report 32; Cooperative Research Centre for Coastal Zone Estuary and Waterway Management (CRC-Coastal), Indooroopilly, QLD, Australia, September 2005; p. 130.

3. Schettini, C.A.F.; Almeida, D.C.; Siegle, E.; Alencar, A.C.B. A snapshot of suspended sediment and fluid mud occurrence in a mixed-energy embayment, Tijucas Bay, Brazil. Geo Mar. Lett. 2009, 30, 47-62.

4. McAnally, W.H.; Teeter, A.; Schoellhamer, D.; Friedrichs, C.; Hamilton, D.; Hayter, E.; Shrestha, P.; Rodriguez, H.; Sheremet, A.; Kirby, R.; et al. Management of fluid mud in estuaries, bays, and lakes. II: Measurement, modeling, and management. J. Hydraul. Eng. ASCE 2007, 133, 23-38.

5. Miyamoto, T.; Fukami, K.; Chikushi, J. Simultaneous measurement of soil water and soil hardness using a modified time domain reflectometry probe and a conventional cone penetrometer. Soil Use Manag. 2012, 28, 240-248.

6. Vaz, C.M.P.; Hopmans, J.W. Simultaneous measurement of soil penetration resistance and water content with a combined penetrometer-TDR moisture probe. Soil Sci. Soc. Am. J. 2001, 65, 4-12.

7. Kosugi, K.; Yamakawa, Y.; Masaoka, N.; Mizuyama, T. A combined penetrometer-moisture probe for surveying soil properties of natural hillslopes. Vadose Zone J. 2009, 8, doi:10.2136/vzj2008.0033.

8. Eijkelkamp. Penetrologger Operating Instructions; Eijkelkamp: Giesbeek, The Netherlands, 2010.

9. Leica Geosystem A. Leica GPS1200+ Series High Performance GNNS System; Leica Geosystem: Heerbrugg, Switzerland, 2008.

10. Seyfried, M.S.; Grant, L.E.; Du, E.; Humes, K. Dielectric loss and calibration of the hydra probe soil water sensor. Vadose Zone J. 2005, 4, doi:10.2136/vzj2004.0148.

11. Stenvens ${ }^{\circledR}$ Water Monitoring System, Inc. The Hydra Probe ${ }^{\circledR}$ Soil Sensor: Comprehensive Stevens Hydra Probe; Users Manual 92915; Stenvens ${ }^{\circledR}$ Water Monitoring System, Inc.: Portland, OR, USA, 2007; pp. 1-63.

12. Seyfried, M.S.; Grant, L.E. Temperature effects on soil dielectric properties measured at $50 \mathrm{MHz}$. Vadose Zone J. 2007, 6, doi:10.2136/vzj2006.0188.

13. Loiskandl, W.; Buchan, G.; Sokol, W.; Novak, V.; Himmelbauer, M. Calibrating electromagnetic short soil water sensors. J. Hydrol. Hydromech. 2010, 58, 114-125.

14. American Society of Agricutlural Engineers. Soil Cone Penetrometer. In ASAE Standards, Engineering Pratices, and Data (ASAE S313.2); ASAE, Ed.; American Society of Agricutlural Engineers. Soil Cone Penetrometer : St. Joseph, MI, USA, 1994; p. 687.

15. Bengough, A.G.; Mullins, C.E. Mechanical impedance to root growth: A review of experimental techniques and root growth responses. J. Soil Sci. 1990, 41, 341-358.

16. Tekin, Y.; Kul, B.; Okursoy, R. Sensing and 3D mapping of soil compaction. Sensors 2008, 8, 3447-3459. 
17. Topakci, M.; Unal, I.; Canakci, M.; Celik, H.K.; Karayel, D. Design of a horizontal penetrometer for measuring on-the-go soil resistance. Sensors 2010, 10, 9337-9348.

18. Bradford, J.M. Penetrability. In Methods of Soil Analysis, Part 1. Physical and Mineralogical Methods. Agronomy Monograph No. 9; Klute, A., Ed.; Soil Science Society of America, American Society of Agronomy: Madison, WI, USA, 1986; pp. 463-478.

19. Vaz, C.M.P.; Bassoi, L.H.; Hopmans, J.W. Contribution of water content and bulk density to field soil penetration resistance as measured by a combined cone penetrometer-TDR probe. Soil Tillage Res. 2001, 60, 35-42.

20. Bácsatyai, L.; Csaplovics, E.; Márkus, I.; Sindhuber, A. Digitale Geländemodelle des Neusiedler See-Beckens. In Wissenschaftliche Arbeiten aus dem Burgenland Band 97; Burgenländisches Landesmuseum (Amt der Bgld. Landesregierung): Eisenstadt, Austria, 1997.

21. Csaplovics, E. Die land- und seeseitige Ausdehung des Schilfgürtels des Neusiedler Sees. In AGN-Forschungsbericht Neusiedler See; Burgenländisches Landesmuseum (Amt der Bgld. Landesregierung): Eisenstadt, Austria, 1985.

22. Soja, G.; Züger, J.; Knoflacher, M.; Kinner, P.; Soja, A.-M. Climate impacts on water balance of a shallow steppe lake in Eastern Austria (Lake Neusiedl). J. Hydrol. 2013, 480, 115-124.

23. Bellingham, K. The Stevens Hydra Probe Inorganic Soil Calibrations; Portland, OR, USA, 2007.

24. D'Amboise, C.J.L. Development of Profile Measurements Using a Frequency Domain Reflectometry Sensor in a Soft Sludge and Calibration for Use in the Neusiedlersee. M.Sc. Thesis, University of Natural Resources and Life Sciences, Vienna, Austria, June 2012.

25. Müllebner, C. Adaption eines Penetrologgers zur Seebodendetektierung im Neusiedlersee. M.Sc. Thesis, University of Natural Resources and Life Sciences, Vienna, Austria, December 2012.

26. Heine, E.; Prokoph, A.; Kogelbauer, I.; Loiskandl, W. Hydroakustische Erfassung der Morphologie und Sedimentschichtung des Neusiedler Sees. In Internationale Geodätische Woche Obergurgl 2013; Hanke, K., Weinold, T., Eds.; Herbert Wichmann Verlag: Obergurgl, Austria, 2013; pp. 64-75.

27. Sauer, A.; Böder, V. Parametric Sub-Bottom Profiling in (Extremely) Shallow Lakes. In Proceedings of the 5th Workshop "Seabed Acoustics", Rostock, Germany, 17-18 November 2011.

(C) 2013 by the authors; licensee MDPI, Basel, Switzerland. This article is an open access article distributed under the terms and conditions of the Creative Commons Attribution license (http://creativecommons.org/licenses/by/3.0/). 